\title{
NOTA BIBLIOGRÁFICA
}

\section{De cómo los árabes realmente invadieron Hispania}

\section{On How the Arabs Actually Conquered Hispania}

\author{
Eduardo Manzano \\ IH, CSIC, España
}

La célebre tesis de I. Olagüe que planteaba la imposibilidad de que los árabes realmente hubieran conquistado Hispania ha recibido en los últimos años un renovado e inaudito impulso merced a una serie de factores: su difusión en foros de internet, su adopción como narrativa histórica por parte de comunidades musulmanas $\mathrm{y}$, finalmente, los intentos de adaptarla como discurso histórico que permita mostrar una supuesta continuidad cultural con el mundo clásico. El reciente libro de Alejandro García Sanjuán constituye una excelente respuesta a esta interpretación. De una forma pormenorizada y sistemática, García Sanjuán desmonta uno por uno los errores y falacias en los que se basa la argumentación negacionista. La obra también contiene algunas interesantes aportaciones críticas sobre la conquista del año 711 que son discutidas en profundidad.

Palabras clave: al-Andalus; Hispania; Conquista árabe; 711; Olagüe.
The well-known thesis by I. Olagüe that suggested that the Arabs did not actually conquer Hispania has received a fresh and outlandish momentum in the last years thank to a number of factors: its diffusion in internet forums, its adoption as a historical narrative by Islamic communities and, finally, the atempts to adapt it as a historical discourse which allows to show a supposed cultural continuity with the classical world. The recent book by Alejandro García Sanjuán is an excellent answer to this interpretation. García Sanjuán tackles with precision and minute detail all the misunderstadings and phalacies on which negationism bases its claims. The work also contains interesting critical contributions to our knowledge of the conquest of 711, which are discussed in detail.

Key words: al-Andalus; Hispania; Arab Conquest; 711; Olagüe.

García Sanjuán, Alejandro, La conquista islámica de la península Ibérica y la tergiversación del pasado, Madrid, Marcial Pons, 2013, 496 pp.

No creo que este haya sido el libro que Alejandro García Sanjuán hubiera querido escribir. Un autor que ha producido brillantes investigaciones sobre 
los bienes habices en al-Andalus, sobre la configuración del territorio islámico de Huelva, o sobre la violencia en la sociedad musulmana, seguramente tiene retos intelectuales más apasionantes que el dedicar casi quinientas páginas a demostrar la veracidad de un suceso histórico conocido por cualquier alumno de primaria. Y, sin embargo, este es un libro importante y, sobre todo, muy necesario. La especie de que en el año 711 los árabes no habrían conquistado militarmente Hispania, siendo al-Andalus el resultado de un proceso pacífico de aculturación, ha ido ganando espacio y atención en proporción directa a lo disparatado de la propuesta. Generalmente, ante este tipo de dislates -y la historia andalusí es un campo abonado para ellos- la actitud de los especialistas suele ser el resignado encogimiento de hombros, el desdén escéptico de quien espera que la magnitud del desatino acabe provocando su olvido. No ha ocurrido así, sin embargo, con esta idea desde que en 1969 un autor vasco vinculado a los círculos fascistas antes de la Guerra Civil, Ignacio Olagüe, publicara un libro titulado Les arabes n'ont jamais envahi l'Espagne, que fue más tarde traducido al español por la Fundación Juan March en 1974. Desplegando una aplastante lógica propia de tertulia de café, Olagüe sentenciaba la imposibilidad de que los árabes de los siglos VII y VIII hubieran tenido la capacidad logística de extender sus ejércitos a lo largo de los inmensos territorios que las fuentes dicen que habrían conquistado. El núcleo central de la obra de García Sanjuán -los capítulos II y III- está dedicado a demostrar lo infundado de la ocurrencia. Ni que decir tiene que lo consigue plenamente con una demostración exacta, plena de erudición, y en la que no queda resquicio ni a la duda, ni a la argumentación alternativa. El exhaustivo análisis que García Sanjuán hace de las evidencias materiales - monedas y sellos de plomo-, de las fuentes latinas - no sólo la Crónica de 754, sino también la llamada Continuatio Bizantino-Arábiga, el Liber Pontificalis, las obras de Beda el Venerable, Paolo Diacono y otros autores- y también de las vilipendiadas y, generalmente, mal comprendidas fuentes árabes, le permite desmontar la «falacia de la inexistencia de testimonios coetáneos»», que han venido manteniendo los defensores de las tesis de Olagüe. Lo que dicen esos testimonios es además incontrovertible: llegaron conquistadores árabes y también bereberes enrolados en sus ejércitos, y su número no constituyó un simple puñado de gentes, sino que contaba por decenas de miles a sus guerreros.

García Sanjuán aplica la misma minuciosidad a desmontar el mayor sinsentido de la tesis de Olagüe: el que fabula que, ante la ausencia de árabes conquistadores, lo que se habría producido en Hispania a comienzos del siglo VIII habría sido una lucha entre facciones del reino visigodo, una de ellas pro-arriana, que sólo la elaboración histórica posterior habría convertido en árabes musulmanes. No hay respaldo alguno para tal idea en la evidencia existente, que demuestra más allá de cualquier duda razonable el carácter árabe e islámico de la conquista. Consciente, sin embargo, de estar lidiando con un discurso seudo-histórico repleto de medias verdades y sofismas, García Sanjuán despliega una argumentación implacable, minuciosa e indiscutible en sus datos, que no deja el más mínimo cabo suelto, y que apabulla por lo palmario de sus conclusiones: un trabajo ingrato - a nadie le apetece demostrar que la Tierra es redonda- pero también necesario, pues como él mismo afirma pa- 
rafraseando a Edmund Burke, para que un fraude prospere «sólo es necesario que los historiadores profesionales no se hayan ocupado de refutarlo de manera sistemática» (p. 144). No creo que después de la lectura de estas incontrovertibles páginas, nadie se atreva a proclamar siquiera el carácter «interesante», «desmitificador», o «provocador» de lo que no es más que la disquisición de un diletante ocioso.

El problema, sin embargo, reside en que esta disquisición, que no debería haber merecido más atención que la del olvido, haya sido tomada en serio por ciertos historiadores y arabistas, citada, e incluso presentada como una sólida y posible alternativa frente a una supuesta historia oficialista. Cómo ha sido posible tal cosa es la pregunta que plantea Alejandro García Sanjuán en el primer capítulo de esta obra, y las respuestas que ofrece deberían hacernos reflexionar; y mucho. Porque este peculiar recorrido por la galería de los horrores historiográficos pone al descubierto algunas miserias de nuestro medio académico e intelectual. Una de ellas, y no menor, es la incapacidad que tradicionalmente ha mostrado el nacionalismo español para entender la conquista árabe. La ocurrencia de Olagüe no era más que una vuelta de tuerca a la célebre "gota de anilina roja vertida en las aguas de un estanque», con la que Julián Ribera gustaba ilustrar una conquista supuestamente realizada con efectivos mínimos y que apenas habría afectado a la esencia patria. El plan de Olagüe era demostrar que la célebre gota ni siquiera habría sido necesaria: el genio de la nación española se las habría arreglado por sí solo para producir la «civilización hispano-árabe». El interés que ello ha llegado a concitar en círculos historiográficos e intelectuales refleja una postura desdeñosa o ignorante del trabajo de los especialistas, empeñada en ahormar el pasado a las percepciones del presente, e inasequible a cualquier conocimiento que no sustente los graves pronunciamientos sobre «el ser de España y los españoles» que, al parecer, cualquiera con un leve o trasnochado conocimiento del pasado andalusí tiene la obligación de pronunciar. Y todo esto sin que se pueda argüir que los argumentos de Olagüe no habían sido rebatidos, pues es bien conocido que Pierre Guichard ya había publicado en 1974 un demoledor artículo contra sus tesis titulado «Les arabes ont bien envahi l'Espagne» en la no precisamente desconocida revista Annales E.S.C.

García Sanjuán muestra además cómo un simple cambio de sujeto y una conveniente adaptación de latitudes han permitido al nacionalismo andaluz engancharse a la idea de la llegada pacífica de la arabidad y del islam para conformar la esencia del pueblo andaluz y, de paso, justificar la subvención de la Junta de Andalucía a la reedición de la obra de Olagüe en 2004. La increíble capacidad de torsión de los discursos historicistas se demuestra también en que este engendro del nacionalismo español haya sido igualmente adoptado por círculos de conversos españoles al islam, que han acogido con entusiasmo la idea de que la llegada del islam habría tenido un carácter pacífico. En esto jugó un papel destacado el filósofo converso Roger Garaudy, «el más grande filósofo europeo desde Platón y Aristóteles» según Muammar al-Gadafi, y a quien se debe una interpretación de la presencia del islam en la Península que ha tenido enorme repercusión en foros y páginas de Internet, tal y como ha señalado Maribel Fierro. 
La guinda a todo este embrollo de actitudes españolistas, andalucistas o islamistas, de intelectuales despistados, de historiadores poco rigurosos, de eruditos locales ávidos de mostrar conocimientos inéditos, y de publicistas amantes de las teorías de la conspiración, la ha acabado poniendo un arabista reconocido, Emilio Gonzalez Ferrín, en una obra titulada Historia General de al-Andalus, que es un compendio de todos estos dislates en nombre de la reivindicación del legado islámico como parte consustancial a la idea de Europa. Desgraciadamente, esta segunda parte de la argumentación ha quedado eclipsada por el interés del propio Gonzalez Ferrín en presentarse como adalid de una tesis rompedora y formulada a contracorriente, lo que ha sido saludado con el alborozo imaginable por los amantes del embrollo, encantados de tener un «libro reciente» que confirmaría sus teorías, un «profesor universitario» que les daría el lustre académico del que carecían, y un «arabista de prestigio» que certificaría la conspiración urdida por historiadores oficialistas. No es, pues, de extrañar que una parte importante de la demostración de García Sanjuán esté encaminada a desmontar esta obra, que ha conocido varias ediciones -otra demostración de nuestras miserias- y que ha venido a otorgar una inaceptable respetabilidad a la ocurrencia de que los árabes no conquistaron $\mathrm{His}$ pania. Tras la lectura de la obra de García Sanjuán el veredicto es tan inapelable que creo que González Ferrín se haría y nos haría un gran favor a todos si rectificara y se centrara de manera más decidida y mejor documentada en su proyecto intelectual de reivindicación del legado islámico dentro del contexto occidental, que sin duda hoy es más necesario que nunca.

El último capítulo se centra en una propuesta de reconstrucción de la conquista a partir de datos y bibliografía disponibles. Tras revisar el problema historiográfico sobre la debilidad o fortaleza del reino visigodo en su última época, García Sanjuán recoge las fuentes analizando sus contradicciones y las interpretaciones que de ellas es posible extraer. Con una exposición brillante y concisa, el autor plantea perspectivas y también críticas en un debate ya normalizado, en el que argumentos rigurosos se exponen con el objetivo de fomentar el avance del conocimiento; un avance que, por cierto, ha sido espectacular en los últimos años, frente a quien piensa que la Historia es una disciplina en la que nos limitamos a dar vueltas a los mismos temas de manera recurrente. Es en el marco de este estimulante debate en el que me gustaría situar algunas consideraciones frente a las críticas que se plantean en este último capítulo a aspectos de mis propios trabajos sobre la conquista.

Plantea García Sanjuán, en efecto, que la interpretación que yo mantengo sobre la importancia que tiene en las fuentes la forma en que se produce la conquista de al-Andalus presenta ciertas inconsistencias. En concreto, García Sanjuán no acaba de estar convencido de que los relatos que narran la conquista de al-Andalus por la fuerza de las armas hayan sido inspirados en los círculos omeyas, mientras que aquellos que subrayan la idea de pactos habrían estado ligados a intereses de los conquistadores opuestos a los de aquéllos. García Sanjuán aprecia en mi tesis un cierto «esquematismo reduccionista», ya que los relatos de las crónicas árabes presentan una visión mixta del proceso de conquista (pp. 431 y 432). Tampoco le parece convincente vincular las noticias de las fuentes con los preceptos jurídicos mālikíes, dado que, por 
una parte, estos no se encontraban conformados en el momento de la conquista $\mathrm{y}$, por la otra, tampoco puede deducirse que los descendientes de los conquistadores estuvieran interesados en una visión de la conquista por capitulación, ya que «lo que beneficiaba los intereses de los árabes era la conquista violenta, única posibilidad de legitimar su posesión como parte del reparto del botín» (p. 438).

La respuesta a estas consideraciones -algunas de ellas muy pertinentes, pues es cierto que señalan ciertos titubeos en algunos de mis primeros trabajos sobre el tema y ponen también de relieve alguna ambigüedad en mis exposiciones- puede abordarse desde varios frentes. El primero lo pone de manifiesto García Sanjuán al citar un pasaje del cadí 'Iyāọ, que también había sido utilizado por mí, y en el que este jurista responde a una consulta sobre la legalidad de la venta de iglesias pertenecientes a cristianos expulsados por apoyar las campañas de Alfonso VII en al-Andalus en pleno siglo XII (p. 420). 'Iyāḍ cita la opinión de Mālik, quien señalaba que la legalidad de la venta dependía de «cómo» se hubiera realizado la conquista del territorio en cuestión: si había sido por la fuerza de las armas se trataba de un bien inalienable en manos de la comunidad musulmana, pero si la conquista había sido por capitulación no había obstáculo para la venta. Este testimonio demuestra que, transcurridos cuatrocientos años desde la conquista, la forma en que ésta se había realizado seguía teniendo una dimensión legal, hasta el punto de que el argumento histórico podía vedar el acceso a una determinada propiedad si se argüía que había sido conquistada por la fuerza de las armas. Creo que esto confirma plenamente mi punto de partida: el problema de la conquista, tal y como se planteó a partir de un determinado momento, no era meramente histórico, sino también jurídico. Pero es que además, y a pesar de señalar que el asunto era «dudoso», el cadí 'Iyāḍ sostenía que, de acuerdo a los alfaquíes conocedores de la historia, parte de al-Andalus se había conquistado por la fuerza y parte lo había sido por capitulación, cayendo la mayor parte de los bienes de los protegidos (amwāl al-mu 'āhadìn) dentro de la primera categoría. El hecho de que el cadí 'Iyāḍ considerara el asunto como algo «dudoso» es algo que no creo que invalide mi tesis, tal y como pretende García Sanjuán, pues habían transcurrido cuatrocientos años desde la conquista y es lógico que a 'Iyāḍ y a sus contemporáneos el asunto les pareciera complejo y enrevesado. A pesar de esta reserva, el jurista mālikí dejaba claro que los que conocían la historia afirmaban que la mayor parte de al-Andalus había sido conquistado por la fuerza y la otra parte por capitulación: eso era exactamente lo que había dictaminado 'Abd al-Malik b. Habīb, el autor al que debemos buena parte de la elaboración de la tradición omeya sobre la conquista.

En este sentido, cada vez me parece que hay más evidencias que apuntan a que en el primer tercio del siglo IX se produjo una revisión de las condiciones en las que se había producido la conquista cien años antes. Ello coincidió con la adopción del rito mālikí por parte de la dinastía omeya y con un proceso de centralización e incremento de la presión fiscal del emirato. La revisión estuvo acompañada de una profunda reelaboración de las tradiciones históricas sobre la conquista, y en ello desempeñó un papel crucial un ulema cercano a los círculos e intereses omeyas: 'Abd al-Malik b. Habīb. Este autor tuvo 
que recurrir a tradiciones elaboradas por juristas mālikíes egipcios, dado que las locales recogían la existencia de pactos generalizados. Pese a ser más ajustadas a lo que realmente debía de haber ocurrido, estas tradiciones no convenían a los intereses omeyas tanto como las elaboraciones egipcias, que habían venido reflexionando sobre el complejo y conflictivo tema de las tierras conquistadas durante la expansión árabe. A lo largo del siglo VIII/II H. esta reflexión había sido confusa y muy contradictoria, pero en época de 'Abd al-Malik b. Habīb sus conclusiones estaban ya establecidas. Debe quedar claro, pues, que estas conclusiones en absoluto estuvieron presentes en el momento de la conquista: esto es algo que yo nunca he defendido, a pesar de que García Sanjuán me lo achaca al señalar que «difícilmente los postulados de Mālik b. Anas podrían haber ejercido influencia sobre la situación legal de las tierras conquistadas», dado su nacimiento en las fechas de la conquista de la Península (p. 435). La diferencia entre tierras conquistadas por la fuerza o por pacto sólo alcanza su plena formulación en los círculos mālikíes a finales del siglo VIII/II H., algo que ya señalaron autores como F. Lokkegaard o A. Noth, y es de ahí de donde lo toma 'Abd al-Malik b. Habīb. En ningún caso debe retrotraerse a momentos anteriores. Yo, desde luego, nunca lo he hecho, y ello creo que invalida una parte sustancial de la crítica de García Sanjuán.

Ahora bien, García Sanjuán considera que «no hay motivos suficientes para calificarlos [a 'Abd al-Malik b. Habīb y al egipcio Ibn 'Abd al-Hakam] como «firmes partidarios» de la idea de que al-Andalus había sido conquistada por la fuerza de las armas» (p. 431), lo que sí que constituye una seria objeción a mi tesis. Mi opinión, en cambio, es que sí hay motivos para pensar así. Para ello me baso en unos textos recogidos por un autor tardío, 'Abd alWahhāb al-Gassānī, quien en el año 1690 vino a España para realizar gestiones por encargo del sultán de Marruecos destinadas a lograr la liberación de ciertos cautivos musulmanes. Al-Gassānī incorporó a su obra testimonios diversos referidos a la conquista de al-Andalus, que sabemos son fiables pues recogen textos que coinciden literalmente con pasajes de otras compilaciones bien conocidas como es el caso del Fath al-Andalus. Uno de los textos que incluye 'Abd al-Wahhāb al-Gassānī no aparece, sin embargo, en ninguna otra fuente conocida y está tomado, pienso, de una obra de al-Rāzì que no aparece transmitida por otros compiladores. En ese texto se recoge un pasaje muy importante, atribuido a 'Abd al-Malik b. Habīb, en el que se da la clave del problema. En él se afirma que el gobernador al-Samh (718-721/100-112) había realizado una distinción entre tierras conquistadas por la fuerza y tierras de capitulación para deducir el quinto, haciendo entrar en éste la muṣallà cordobesa. Al-Samh escribió luego al califa con lo que había hecho en el ard 'anwatan y en el ard al-šammāl, siendo esta última, es decir, la tierra del norte, la que había sido conquistada mediante un pacto, ya que sus habitantes se habían comprometido a pagar la ŷizyà correspondiente a una tercera o cuarta parte de sus productos según la calidad de sus tierras. Es en este texto en el que me baso para afirmar que 'Abd al-Malik b. Habīb sostenía que al-Andalus había sido conquistado por la fuerza de las armas, mientras que los territorios septentrionales eran los sometidos por capitulación. Ello se aviene a la perfección con un pasaje del $K$. al-Ta'rīj, citado por el propio García Sanjuán 
(p. 419), en el que se señala que Ŷillīqiyya había sido conquistada por capitulación (sulh). Así, pues, la tesis de 'A bd al-Malik b. Habīb para solucionar el embrollo de la conquista era evidente: los territorios de capitulación eran los del norte y por eso estaban obligados a pagar un tributo frente al que generalmente remoloneaban, razón por la que era necesario enviar aceifas que recordaran las obligaciones contraídas. El resto de al-Andalus, en cambio, era territorio conquistado por la fuerza. Esta es la misma idea de la que se hace eco cuatrocientos años más tarde el cadí 'Iyā cuando sostiene que parte de al-Andalus se había conquistado por la fuerza y parte lo había sido por capitulación, cayendo la mayor parte de los amwāl al-mu 'āhadīn dentro de la primera categoría.

En Ibn 'Abd al-Hakam y en los círculos mālikíes egipcios esas ideas habían estado ya presentes, aunque su grado de elaboración había sido forzosamente menor que el realizado por el ulema andalusí. Es cierto que, como señala García Sanjuán, Ibn 'Abd al-Hakam no hace en su Futūh Miṣr una valoración global de la conquista como producida por «la fuerza de las armas», pero no veo cómo podrían entenderse las abundantes menciones que este autor hace al botín, a la existencia de «fraudes» o a la reserva del «quinto» (jums), si hubiera pensado que la conquista se había realizado mediante pactos. Sin una conquista por la fuerza no puede haber botín, no puede haber fraudes y, desde luego, no puede haber quinto.

Si ya de por sí es extraordinario que 'Abd al-Malik b. Habīb recurriera a tradiciones foráneas para narrar la conquista, más aún lo es que Aḥmad alRāzī mantuviera un siglo después el mismo cañamazo narrativo desde una perspectiva también favorable a los gobernantes omeyas. Creo que ello evidencia la fijación de una memoria histórica del suceso férreamente controlada por esta dinastía. De hecho, el análisis detallado de los relatos de la conquista no debería sorprender tanto por las contradicciones que éstos presentan, como por sus similitudes, algo que se evidencia cuando se comparan los textos árabes, tal y como he intentado hacer en un trabajo reciente titulado Los relatos de la conquista de al-Andalus en las fuentes árabes: un estudio sobre su procedencia (disponible en www.digitalcsic.es). Este trabajo de comparación textual permite deshacer ciertos errores de atribución muy frecuentes: así, por ejemplo, no es cierto que al-Rāzì describa la conquista de Sevilla mediante capitulación ante Tāariq, tal y como sostiene García Sanjuán (p. 397): lo que ocurre es que al-Maqqarī compila esta información mezclándola con el texto de al-Rāzî que también está siguiendo; en la versión de al-Rāzī (y no de Ibn Hayyān como piensa García Sanjuán) Sevilla cae en manos de Mūsà b. Nușayr tras varios meses de asedio y luego además se rebela teniendo que ser sometida de nuevo. De hecho, en la versión del cronista califal, las campañas suelen culminar con tomas realizadas por la fuerza, excepto Tudmīr (aunque tiendo a pensar que al-Rāzī no citaba el texto del célebre pacto) y Mérida. En este último caso el tratado de capitulación es muy peculiar, pues establece que debían pasar a los musulmanes los bienes de quienes hubieran muerto durante el asedio, así como las propiedades de la Iglesia o de quienes hubieran huido al norte. No resulta comprensible la salvedad con respecto a las propiedades eclesiásticas o a las herencias de los fallecidos en combate-compá- 
rese con el pacto de Teodomiro- por lo que esta peculiaridad a buen seguro debe ponerse en relación con la afirmación de Ibn al-Qūtiyya cuando señala que existían discusiones sobre si Mérida había sido conquistada por la fuerza o mediante capitulación. Si unimos a esto los ya citados pasajes de la Risāla del embajador marroquí, creo que pocas dudas puede haber de que al-Rāzî consideraba que en efecto el conjunto de al-Andalus, excluyendo los territorios del norte y casos muy concretos, había sido tomado por la fuerza de las armas.

Es evidente que una concepción histórica así tenía serias consecuencias: siglos más tarde todavía el cadí 'Iyā ̣̣ señalaba que los bienes de una iglesia no podían venderse si se encontraban en un territorio conquistado por la fuerza de las armas. Pero es que además esa concepción chocaba con tradiciones que atestiguaban pactos generalizados. Y es ahí donde creo que radica la razón de las contradicciones de nuestros textos e incluso esa «visión mixta» del proceso de conquista de la que habla García Sanjuán. Había que superponer tradiciones distintas e incluso negociar sobre ellas y el resultado tenía que ser forzosamente contradictorio. Sólo así se entiende que narraciones que parecen remontarse a un autor también perteneciente a los círculos palatinos omeyas, 'Arīb b. Sa'd, presente aspectos que contradicen la narración de al-Rāzì. ¿Por qué este último autor nos dice que Écija se conquista después de un combate encarnizado, mientras que en la otra narración de habla de un pacto? ¿por qué, como veíamos, al-Rāzī nos habla de Sevilla conquistada tras un asedio y rebelándose después - claro rasgo de un territorio conquistado por la fuerza-, mientras que la otra narración nos habla de un pacto y del pago de la ŷizyà? ¿por qué algunas fuentes nos hablan de pruebas de la existencia del quinto en al-Andalus, mientras que Ibn al-Qūtiyya negaba su existencia? Tomemos, en fin, el caso del Cementerio del Arrabal en Córdoba del que se nos dice que habría formado parte del «quinto» separado por Mūsà, pero cuyos límites eran objeto de disputa todavía en pleno siglo X/IV H., tal y como nos cuenta alJušanī. Parece que estamos asistiendo a un cruce de discusiones que no entendemos siempre bien y en el que es cierto que no se puede caer en un esquematismo, dado que todos los contendientes estaban integrados de una forma $u$ otra en los círculos omeyas. Ahora bien, se podía estar integrado en esos círculos y propugnar una visión histórica que abiertamente contradecía la redactada por los cronistas de la dinastía, tal y como pone de relieve el evidente caso de Ibn al-Qūtiyya.

A mi modo de ver, los argumentos históricos tenían una dimensión legal y también fiscal y es por ello por lo que no comparto la idea de García Sanjuán en el sentido de que «es dudoso que, en pleno califato, fuese necesario justificar la percepción del diezmo» o que «la forma de sumisión del territorio resulta indiferente a efectos fiscales y lo que importa es la confesión del propietario» (pp. 436-437). Quizá en época califal no fuese ya necesario justificar la introducción del diezmo, pero sí que debió de serlo indudablemente a comienzos del siglo IX -el momento de la reelaboración histórica de la conquista- como bien ponen de manifiesto revueltas como la del Arrabal de Córdoba que estuvieron motivadas por la generalización de este impuesto, tal y como claramente recoge el tomo II del Muqtabis. Por lo demás, los trabajos 
de P. Chalmeta han demostrado que a efectos fiscales la confesión del propietario dejó de ser significativa ante el aumento de las conversiones al islam, siendo en cambio el status de la tierra lo que contaba para las estimaciones fiscales. Y todo indica que para definir ese status la forma en que se había realizado la conquista todavía podía tener influencia, al menos a comienzos de siglo IX/II H. Cien años después, y por razones que desconocemos, el asunto seguía estando vigente. Dos siglos más tarde también.

Creo, pues, que la crítica de A. García Sanjuán no consigue en absoluto derribar mi propuesta de ver en los relatos dominantes de la conquista una proyección de la ideología omeya que buscaba legitimar el estatuto de al-Andalus como territorio conquistado por la fuerza de las armas, frente a los intereses de los descendientes de los conquistadores y de la propia aristocracia indígena que pretendían hacer valer la fuerza de dichos pactos. Es cierto que no pueden definirse dos bandos claramente definidos - estamos hablando de la misma élite andalusí- pero esta diferencia debió de provocar graves polémicas. Tengo por muy probable que ciertas rebeliones de época emiral estuvieran motivadas por el cambio de status de ciertos territorios que los Omeyas estaban intentando forzar. El embrollo debió de ser considerable y es posible incluso rastrearlo en el autor de una crónica astur, la llamada Crónica Profética, que estaba perfectamente informado sobre los asuntos andalusíes y que, al narrar la conquista, habla de pactos establecidos entre conquistadores y conquistados señalando que consecuencia de dichos pactos, estos últimos habían visto su condición reducida a la de siervos armis conquisiti, un calco lingüístico del árabe 'anwatan, lo que confirma la importancia de la noción.

Naturalmente, todas estas discrepancias no empecen para considerar este libro como una obra importante y necesaria, que despeja el camino de polémicas innecesarias, esperemos que de una vez por todas. El soberbio trabajo de García Sanjuán, las críticas que plantea y los argumentos que aquí he expuesto son, creo, igualmente indicadores del gran avance que hemos conseguido en el estudio de la conquista árabe en estas últimas décadas y que todo parece indicar que no hará más que profundizarse en los tiempos venideros.

Recibido: 07/01/2014

Aceptado: 28/02/2014 